is at McBurney's point. Delbet thinks the reason for this usual tenderness at McBurney"s noint is secondary infection of the inter-ileocecal glands.

It is rare that a first attach of appendicitis perforates. This is not the first attack in this case. The present attack bergan suddenly night before last at $11: 30$ oclock, and he entered the hospital yesterday noon, when the best treatment was institutel, viz: rest, diet, ice, with the usual effect-relief. Last night without imprudence, with no cessation from the above named treatment, the patient was seized with a new violent attack. It is 110 w relieved. This is the symptom-return of the pain in the form of a crisis, in spite ct treatment-which makes me give the lia!nosis of perforation.

Delbet then cites several similar cases, and discusses the leucocyte count, and the נron.r time to operate in case there is no perfo:ation, concluding that it is better to wait usuaily tii!? the interval. The factor that determines when the attack has subsided is the return of the temperature to normal. Operation revealed a perforated appendix.

(W. A. B.)

\title{
EYE, EAR, NOSE AND THROAT
}

\section{HEMORRHAGE FOLLOWING QLINSY.}

Ligation of Common Carotid Artery; Recovery. With a Stucly of Fifty-one Cases of Hemorrlage in Connection with Plaryngeal Suppurations. By Janes E. Newcomb, M.D., New York City. in London Journal of Laryngology, Rhinology, and Otology. June, 1908.

Dr. Newcomb reports case of stout, plethoric German, aged 55. Good liver, and free consumer of alcohol. Vicssels showed distinct arterio sclerosis. No renal trouble. Had numerous quinsies extending over perio: 1 of 40 years. No previons attack for ten years. On Feb. 3, 1908, had an attack affecting both tonsils. On Feb. 6 pointing was observed far out in soft palate on left side, which was incised by Dr. McBarron. At a depth of 3-8 of an inch a cavity was entered, and a drachm of pus voided. Thirty-six hours later bleeding recurred from incision distinctly arterial in color. Dr. Newcomb was called in with Dr. McBarron, and the cavity packed with gauze dipped in aceto-tartrate of alum. Bleeding did not recur for thirty-six hours, but was more persistent and increased in amount. Packing and ice internally and externally did not control the hemorrhage and resort was had to ligation of the left common carotid. Bleeding ceaserl instantly and never returned. Patient made good recovery and there was no disturbance of cerebration.

He reports fifty adllitional cases from the literature. There were eleven cases of spontaneous opening of the abscess, followed by inmerliate hemorrlage witl seven deaths and four recoveries. In all four recovcries ligation of common caroticl was resorted to. In the seven fatal cases no operation was done. The cause of the fatal hemorrhage in eacl case was ulceration of internal carotid.

There were fifteen cases of spontaneous openings of the abscess with secondary hemorrhage, followed by eight deaths and seven recoveries. In the eight fatal cases there was no operation. In the seven recoveries there were four ligations.

There were seven cases of abscess opened by incision with immediate hemorrhage, which were followed by four deaths and three 
recoveries. In the fatal cases two had the common caroticl ligated. In one the fatal liemorrhage oectrred on the 28th day in the other the ligature ditl not control the hemorrhage. In the three reeovered eases ligation was performed in two.

There were eight eases of abseess opened by incision followed by secondary hemorrhage, with four fatalities and four recoveries. In the four fatal cases there was higation of the conmon caroticl in three. In the four recorered eases henorrhage was eontrolled by iee, rest and packing without ligation.

In five cases of hemorrhage following retropharyngeal abseess there were two deaths and three recoveries. In the three recoveries there were two ligations and none in the two fatal cases.

There were three cases of hemorrhage in connection with scarlatinal suppuration, with one reath and two reeoveries. No operation in fatal ease; ligation of common carotid in one of the recovered cases.

There were two cases of gangrenous tonsilitis with spontaneous opening and death in both cases. No operation was done.

Of the 51 cases reported there were 23 recoveries and 28 deaths, a mortality rate of 54.9 per cent. The common carotid was igated 16 times with 11 recoveries and five deaths. The external ancl internal carotid were ligated once anil the external, internal and common carotid were ligated once, with recovery in both cases.

Autopsy recorels were given in thirteen cases. The bleeding came from the external caroticl in two, ascending plaryngeal in one, "carotid" in one, lingtual in one, at the bifurcation in one, facial in one. The other cases were from internal caroticl. In ten cases in whieh no autopsy was held the blood was supposed to eome from internal carotid.

(M. M. C.)

\section{. \\ BOOK REVIEW}

A Tert-Book of Winor Surgery. By Edward Nilton Foote, A.M., M.D., Instructor in Surgery, College of Physicians and Surgeons (Columbia University); Lecturer on Surgery, New York Polyelinie Iledical Sehool, ete.

This book, as its name indicates, is not intended to cover the fiell of sirgery, but to give to the working practitioner a condensed and modern understanding of the nore common surgical conditions he will be called upon to attend. The work does not confine itself to the treatment of the lesser ailments, but gives a brief synopsis of the clinical manifestations of many diseases heretofore found only in larger and more exhaustive works on surgery.
It touehes very briefly on all of the practical branches; Gynecology is given about five pages and the subjects discussed are Old Lacerations of the Perineum, Prolapse of the Uterus, Fistula of the Vagina, Adhesions of the Clitoris, Imperforate Hymen and Stenosis of the Cerrix. Diseases of the Rectum, Genito-Urinary Organs and Dermatology are each discussed very briefly from the surgeon's viewpoint.

The book offers no pathology and presents no new inaterial. It abounds in photographs taken from the author's extensive practice, which are valuable in fixing idleas of pathological conditions. The chapter on bandaging is especially to be commencled. The uscless repetition found all through the work we hope will be corrected in future editions. 